\title{
ANALYTICAL STRATEGY BASED ON THE USE OF LIQUID CHROMATOGRAPHY AND GAS CHROMATOGRAPHY WITH TRIPLE QUADRUPOLE AND TIME-OF-FLIGHT MS ANALYZERS FOR INVESTIGATING ORGANIC CONTAMINANTS IN WASTEWATER
}

E. Pitarch ${ }^{1}$, T. Portolés ${ }^{1}$, J.M. Marín ${ }^{1}$, M. Ibáñez ${ }^{1}$, F. Albarrán ${ }^{2}$, F. Hernández ${ }^{1 *}$

${ }^{1}$ Research Institute for Pesticides and Water, University Jaume I, 12071 Castellón, Spain

Tel: +34 964 387366, Fax: +34 964 387368, E-mail: felix.hernandez@qfa.uji.es

${ }^{2}$ RECIPLASA, Reciclados de Residuos La Plana, S.A., 12200 Onda, Castellón, Spain 


\section{ABSTRACT}

The presence of a wide variety of organic pollutants with different physico-chemical characteristics has been investigated in wastewater samples from a municipal solid waste treatment plant placed at Castellón, Spain. An advanced analytical strategy has been applied, consisting on the combined used of two powerful and complementary techniques, GC and LC, both hyphenated with tandem mass spectrometry with triple quadrupole analyzers. The GC-MS/MS method was based on sample extraction using $\mathrm{C}_{18}$ SPE cartridges and allowed the determination of around 60 compounds from different chemical families, such as PAHs, octyl/nonyl phenols, PCBs, organochlorine compounds, insecticides, herbicides and PBDEs. Most of compounds selected are included as priority contaminants in the European Union (EU) Water Directive. The UHPLC-MS/MS method, which provided high chromatographic resolution and sensitivity and short analysis time, used a sample extraction with OASIS HLB SPE cartridges and allowed the determination of 37 (more polar) pesticides.

The methodology developed has been applied to the analysis of 41 water samples (20 non-treated, raw leachates, and 21 treated) collected between March 2007 and February 2009. Treated (reverse osmosis) water samples analyzed rarely exceeded $0.5 \mu \mathrm{g} / \mathrm{L}$ for the contaminants investigated. As expected, in non-treated leachates the number of detections and the concentration levels found were notably higher than in treated waters. The most commonly detected pollutants were herbicides (simazine, terbuthylazine, terbutryn, terbumeton, terbacil and diuron), together with fungicides (thiabendazole and carbendazim) and 4-t-octylphenol. In the light of data obtained, it has been proven that reverse osmosis process used for water treatment was efficient and notably reduced the levels of organic contaminants found in raw leachate samples. 
In order to investigate the presence of other non-target contaminants, water samples were also analyzed by using GC-TOF MS and LC-QTOF MS. Several organic pollutants that did not form a part of the previous list of target contaminants were identified in the samples, thanks to the good sensitivity of TOF MS in full spectrum acquisition mode and the valuable accurate mass information provided by these instruments. The insecticide diazinon, the fungicide diphenylamide, the UV filter benzophenone, N-butyl benzenesulfonamide (N-BBSA), the insect repellent diethyltoluamide, caffeine or pharmaceuticals like erythromycin, benzenesulfonanilide, ibruprofen, atenolol or paracetamol, were some of the compounds identified in the water samples analyzed.

\section{Keywords}

Organic pollutants, wastewater, UHPLC, GC, tandem MS, TOF MS 


\section{INTRODUCTION}

Nowadays, many organic contaminants can be present in environmental water, normally at the $\mu \mathrm{g} / \mathrm{L}$ level or below [1]. One of the routes for the contaminants to enter into the aquatic environment is from municipal solid waste landfill leachates. These leachates frequently contain a variety of hazardous chemicals which may cause severe biological effects in the aquatic environment, as many of them are highly toxic or even carcinogenic [2-3]. Therefore, efficient treatment of landfill leachates is required and monitoring of organic pollutants is compulsory to assure the quality of treated water. When possible, the treatment process should be performed in the Municipal Solid Waste (MSW) treatment plants, generally by the application of membrane technology, which is free of any chemical addition and uses relatively low energy. Membrane filtration, such as micro and ultra filtration or nano filtration, and reverse osmosis could be a choice for the treatment of landfill leachates, depending of the type of particles or salts to be removed.

The selection of the analytical methodology to be applied for water quality control is of outstanding relevance to obtain realistic results, especially in the analysis of treated water that are discharged into the aquatic environment. The development of sensitive and multi-class methods for determination of organic contaminants in wastewater has become a major issue, due to the presence of many different compounds in this type of samples and to the strict legal European Union requirements for water quality [4-6]. General reviews relating to water analysis and emerging environmental contaminants [7-10] have been published over the last 2 years reporting different analytical methodologies and new developments in this field.

Due to the complexity of the wastewater matrices, their high organic matter content, the low analyte levels typically found, and the high variety of organic contaminants with 
quite different physico-chemical characteristics, the complementary use of gas chromatography (GC) and liquid chromatography (LC), both coupled to mass spectrometry (MS), is required to have a realistic and more complete overview of the organic pollution present in these waters. GC-MS has been the major adopted analytical technique to perform multi-residue analysis of volatile and semi-volatile organic pollutants [11]. Nowadays, enrichment via solid-phase extraction (SPE) using relatively low sample volumes followed by GC-MS, or even better, GC coupled to tandem mass spectrometry (MS/MS) is the preferred approach for GC-amenable micropollutants. Ion trap (IT) and triple quadrupole (QqQ) analyzers offer the possibility of adequate precursor and product ion selection, which allows improving sensitivity (reducing the chemical noise in the chromatograms) and selectivity. The use of two stages of mass analysis in MS/MS systems based on QqQ allows working on selected reaction monitoring (SRM) mode, one of the most selective and sensitive approaches at present for quantification and confirmation, especially in trace water analysis. Our own research group has recently reported the determination of more than 50 priority organic pollutants in water by GC-MS/MS with QqQ [12].

For more polar, less or non GC-amenable contaminants, LC-MS/MS is surely the most appropriate analytical technique [13-15], leading to satisfactory results from both the quantification and confirmation point of view. Recently, ultra high pressure liquid chromatography (UHPLC) has been developed as an innovative and powerful separation technique based on the use of stationary phases of particle size $(<2 \mu \mathrm{m})$ smaller than in conventional HPLC. UHPLC coupled to MS/MS has been shown as an excellent analytical tool for multi-class analysis of water for compounds like pharmaceuticals and drugs [16-19], toxins [20] or pesticides [21, 22], due to its improved selectivity and sensitivity. With the modern QqQ analyzers even more than 
two SRM transitions can be acquired for a safe identification without losing sensitivity. Despite the improved sensitivity when using UHPLC-MS/MS, the application of a preconcentration step (e.g. based on SPE) is typically required in multi-class methods where a large number of contaminants are determined [16-22].

Despite the excellent performance of LC-MS/MS and GC-MS/MS methods, qualitative information that supports the recognition and structural elucidation of compounds other than target is still needed to obtain more information on actual water sample composition. Time-of-flight mass spectrometry (TOF MS) is an excellent technique for this purpose. TOF MS provides the selectivity and sensitivity required for an efficient and wide-scope screening, as it combines high full-spectral sensitivity with high mass resolution, allowing any LC-ionizable components in the sample (LC-TOF MS) or GCamenable (GC-TOF MS) to be accurately mass-measured. TOF MS gives a notable amount of chemical information in a single analysis that allows searching for a high number of compounds after MS acquisition. Our own research group has recently reported several applications of both GC-TOF and LC-TOF for investigation of organic contaminants in water samples [23-27].

TOF MS is also a powerful technique for the investigation of non-target compounds, making feasible the elucidation of unknowns without any previous information or analyte selection. On the basis of these improved characteristics, GC has been combined with high-resolution TOF-MS (GC-HR-TOFMS) for non-target screening of GCamenable organic (micro) pollutants in water $[25,26,28,29]$. With regard to LC, very few applications using UHPLC-(Q)TOF MS have been reported in non-target field analysis [27]. 
The aim of this paper is to investigate the presence of a large number of organic pollutants in treated and raw non-treated leachates from a MSW treatment plant. Information on the quality of leachates after the treatment process is required to estimate the feasibility of discharging them into the aquatic environment. For this purpose, an analytical strategy consisting on the combined use of GC-MS/MS and UHPLC-MS/MS, both with triple quadrupole, has been applied in order to detect and quantify 94 target contaminants. Although most of selected analytes are considered as priority pollutants in water, their determination does not surely offer a realistic overview on the samples quality, as only a limited number of contaminants are determined. For this reason, all water samples were also analyzed by GC-TOF MS and LC-QTOF MS in order to widen the searching to other non-target contaminants, giving in this way useful information that could be applied to improve future monitoring programs. 


\section{EXPERIMENTAL}

\section{Reagents and chemicals}

Reference standards of organic contaminants (see Table 1) were purchased from Dr. Ehrenstorfer (Augsburg, Germany), Wellington Laboratories (Guelph, Ontario, Canada), Fluka (Buchs, Switzerland), Riedel de Haën (Seelze, Germany) or Sigma (St. Louis, MO, USA).

Isotopically labelled surrogates used for GC-MS/MS were $p, p^{\prime}-\mathrm{DDE}-\mathrm{d}_{8}$, lindane- $\mathrm{d}_{6}$, benzo(a)anthracene- $d_{12}$ and terbuthylazine- $d_{5}$ (Dr. Ehrenstorfer) and hexachlorobenzene (HCB)- ${ }^{13} \mathrm{C}_{6}$ (Cambridge Isotope Labs, Inc. Andover, MA, USA). Isotopically labeled surrogates used for UHPLC-MS/MS were dimethoate- $\mathrm{d}_{6}$, 2-methyl-4-chlorophenoxy acetic acid (MCPA)- $\mathrm{d}_{3}$, carbofuran- $\mathrm{d}_{3}$, diuron- $\mathrm{d}_{6}$, terbuthylazine- $\mathrm{d}_{5}$, imazalil- $\mathrm{d}_{5}$ and thiabendazole- $\mathrm{d}_{6}$ (Dr. Ehrenstorfer).

To prepare calibration curves, working mix solutions of organic contaminants and isotopically labeled compounds were prepared in hexane or acetonitrile:water (10:90, v/v) for GC-MS/MS or UHPLC-MS/MS, respectively.

Acetone (residue analysis), acetonitrile (HPLC grade), ethyl acetate, dichloromethane and hexane (ultra-trace quality) were purchased from Scharlab (Barcelona, Spain). HPLC-grade water was obtained by purifying demineralized water in a Milli-Q Gradient A10 (Millipore, Bedford, MA. USA). Formic acid ( $\mathrm{HCOOH}$, content $>98 \%$ ) and ammonium acetated $\left(\mathrm{NH}_{4} \mathrm{Ac}\right.$, reagent grade) were supplied by Scharlab.

Cartridges used for solid phase extraction were $500 \mathrm{mg}$ Bond Elut $\mathrm{C}_{18}$ (Varian, Harbor City, CA, USA) and 200 mg Oasis HLB (Waters, Milford, MA, USA). 


\section{Sampling}

Treated (21 samples) and raw leachate (20 samples) water samples were collected monthly from RECIPLASA, a Municipal Solid Waste (MSW) treatment plant sited at the Castellón province (Spain) along the period between March 2007 and February 2009. Treated water was submitted to a reversed osmosis process.

Raw leachate samples were 50-fold diluted with HPLC water before analysis due to their high organic matter content. All samples were stored in the dark at a temperature below $-18^{\circ} \mathrm{C}$. Before analysis, water samples were previously centrifuged at $3500 \mathrm{rpm}$ for $10 \mathrm{~min}$ if suspended particulate matter was present.

\section{LC-MS Instrumentation}

\section{UHPLC-MS/MS}

UHPLC analysis was carried out using an Acquity UPLC system (Waters, Milford, MS, USA), equipped with a binary solvent. The chromatographic separation was achieved using an Acquity UPLC HSS T3 column, $1.8 \mu \mathrm{m}, 100 \mathrm{~mm} \times 2.1 \mathrm{~mm}$ I.D (Waters) at a flow rate of $0.3 \mathrm{~mL} / \mathrm{min}$. The mobile phase consisted of water/methanol gradient (both $0.1 \mathrm{mM} \mathrm{NH}_{4} \mathrm{Ac}$ ). The $\mathrm{LC}$ system was interfaced to a $\mathrm{TQD}^{\mathrm{TM}}$ (quadrupole T-wave quadrupole) mass spectrometer with an orthogonal electrospray ionization source Zspray (Waters). For operation in the MS/MS mode, collision gas was Argon 99.995\% (Carburos Metálicos, Valencia, Spain) with a pressure of $2 \times 10^{-3}$ mbar in the T-wave cell. The additional experimental setups can be found elsewhere [22].

\section{UHPLC-QTOF MS}

An ultra performance Acquity liquid chromatography (UPLC ${ }^{\mathrm{TM}}$ ) system (Waters) was interfaced to a QTOF mass spectrometer (QTOF Premier, Waters) using an orthogonal Z-spray electrospray interface. LC separation was performed using an Acquity UPLC 
HSS T3 column, $1.8 \mu \mathrm{m}, 100 \mathrm{~mm} \times 2.1 \mathrm{~mm}$ I.D at a flow rate of $300 \mu \mathrm{L} / \mathrm{min}$. The mobile phase consisted of water/methanol gradient (both $0.1 \mathrm{mM} \mathrm{NH}_{4} \mathrm{Ac}$ ) where the methanol percentage was changed linearly as follows: $0 \mathrm{~min}, 5 \% ; 7 \mathrm{~min}, 90 \% ; 8 \mathrm{~min}$, $90 \%$; $8.1 \mathrm{~min}, 5 \%$. The injection volume was $20 \mu \mathrm{L}$. TOF-MS resolution was $\sim 10,000$ FWHM (V-mode) at $m / z 556$. The MCP detector potential was set to $1750 \mathrm{~V}$ in positive ionization mode. A cone voltage of $25 \mathrm{~V}$ and a capillary voltage of $3 \mathrm{kV}$ were used. The interface temperature was set to $350{ }^{\circ} \mathrm{C}$ and the source temperature to $120{ }^{\circ} \mathrm{C}$. A scan time of $0.05 \mathrm{~s}$ was chosen. The automated attenuated function (dynamic range enhancement, DRE) was selected to correct possible mass peak saturations, making it feasible to achieve quantification and accurate mass measurements over a wide concentration range. Calibration experiments from 50 to $1000 \mathrm{~m} / \mathrm{z}$ were performed monthly using a mixture of $\mathrm{NaOH} 0.05 \mathrm{M}$ : $\mathrm{HCOOH} \mathrm{10 \%} \mathrm{(50:50).} \mathrm{A} 2 \mathrm{mg} / \mathrm{L}$ standard solution of leucine enkephalin was introduced via the lock spray needle (cone, voltage, $90 \mathrm{~V}$ ) at a flow rate of $30 \mu \mathrm{L} / \mathrm{min}$.

\section{GC-MS Instrumentation}

\section{$G C-M S / M S$}

A GC system (Agilent 6890N, Palo Alto, USA) equipped with an autosampler (Agilent 7683) was coupled to a triple quadrupole (QqQ) mass spectrometer, Quattro Micro GC (Waters), operating in electron ionization (EI) mode. The GC separation was performed using a fused silica HP-5MS capillary column with a length of $30 \mathrm{~m} \times 0.25 \mathrm{~mm}$ i.d. and a film thickness of $0.25 \mu \mathrm{m}$ (J\&W Scientific, Folson, CA, USA). Splitless injections of $1 \mu \mathrm{L}$ sample were carried out. The system operated in MS/MS (SRM) mode using Argon 99,995\% (Carburos Metálicos) as collision gas at a pressure of $2.8 \times 10^{-3} \mathrm{mbar}$ in the collision cell. More detailed information can be found elsewhere [12]. 


\section{GC-TOF MS}

An Agilent 6890N GC system (Paloalto, CA, USA) equipped with an Agilent 7683 autosampler was coupled to a time-of-flight mass spectrometer, GCT (Waters), operating in EI mode. The GC separation was performed using the same characteristics as in the above GC-MS/MS system. The interface and source temperatures were both set to $250^{\circ} \mathrm{C}$ and a solvent delay of 3 minutes was selected. TOF MS was operated at 1 spectrum/s acquiring the mass range $m / z 50-650$ and using a multi-channel plate voltage of $2850 \mathrm{~V}$. TOF MS resolution was about 8500 (FWHM) at $m / z 612$ and heptacosa was used for the daily mass calibration as well as lock mass $(\mathrm{m} / \mathrm{z}$ ion monitored was 218.9856). The application manager TargetLynx, a module of MassLynx software, was used to process the qualitative and quantitative data obtained from standards and samples for target compounds. The application manager ChromaLynx, also a module of MassLynx software, was used to investigate the presence of non-target compounds in samples. Library searching was performed using the commercial NIST library

\section{Analytical procedure}

The UHPLC-MS/MS procedure was based on the previous work developed in our laboratory for the determination of multi-class pesticides in environmental and wastewater samples [22]. Briefly, $100 \mathrm{~mL}$ of water sample acidified with $\mathrm{HCOOH}$ and containing the surrogate internal standards (IS's) was passed throughout an Oasis HLB cartridge, previously conditioned. After elution with $5 \mathrm{~mL}$ acetone, the extract was evaporated and reconstructed with $1 \mathrm{~mL}$ acetonitrile:water (10:90, v/v). $20 \mu \mathrm{L}$ of the final extract was injected in the UHPLC-MS/MS system. Three SRM transitions were acquired for each compound. 
The GC-MS/MS procedure was based on our previous work dealing with the determination of priority of organic contaminants in water [12]. Several of the target compounds are relevant in the field of water policy of the European Union, and in fact are included in Annex X of the Directive 2000/60/EC [5]. Briefly, $100 \mathrm{~mL}$ of water sample containing the surrogate IS's was passed throughout a $\mathrm{C}_{18}$ cartridge previously conditioned. After elution with $5 \mathrm{~mL}$ ethyl acetate:dichloromethane (50:50), the extract was evaporated and redissolved in $1 \mathrm{~mL}$ hexane. $1 \mu \mathrm{L}$ of the final extract was injected in the GC-MS/MS system. Two SRM transitions were acquired for each compound.

All methods applied were previously validated fulfilling the analytical characteristics required in the field of residue analysis. 


\section{RESULTS AND DISCUSSION}

\section{GC-MS/MS and LC-MS/MS target analysis}

The study presented here was a part of a project, which required the determination of around 100 organic pollutants (see Table 1) in treated and raw leachate water samples collected from a MSW treatment plant sited at the Castellón province. The main objective was to investigate the quality of the leachates after treatment with a reverse osmosis process in order to know the feasibility of their dumping into the aquatic environment. Moreover, the analysis of both types of water (treated and non-treated) allowed to evaluate the efficiency of the reverse osmosis process. According to the polarity of target analytes and to our previous experience [13], a modern and efficient analytical strategy, consisting of the combined use of two complementary techniques, GC-MS/MS and UHPLC-MS/MS, was applied. In this way, we were able of widening the scope of the method, covering around 100 target analytes.

This study was carried out between March 2007 to February 2009, and a total of 41 water samples (21 treated and 20 raw leachate) were analyzed. Both methods, GCMS/MS and UHPLC-MS/MS, were applied for the analysis of all samples collected. The acquisition of, at least, two transitions per compound -one for quantification (Q) and one (or two) additional for confirmation $\left(\mathrm{q}_{\mathrm{i}}\right)$ - allowed simultaneous quantification and reliable identification of positive findings. Thus, all findings were confirmed by the compliance of both retention time and $\mathrm{Q} / \mathrm{q}_{\mathrm{i}}$ ratio when compared with a reference standard. Maximum $\mathrm{Q} / \mathrm{q}_{\mathrm{i}}$ deviations accepted were based on the European Commission Decision [30].

Data obtained from the analysis of samples (Figure 1) showed that pesticides were by far the most commonly detected compounds in both treated and raw leachate samples, specially herbicides (phenylurea, triazine, uracil and carbamate), fungicides 
(benzimidazole, conazole and anilide) and insecticides (carbamate, organophosphorus (OP) and phenylthiadiazinone). Other contaminants also frequently found were octyl nonyl phenols (ONP) and polycyclic aromatic hydrocarbons (PAH), detected in almost all raw, and in 86 and 57\%, respectively, of treated water samples. Among pesticides, phenylurea herbicides exceeded the concentration level of $0.1 \mu \mathrm{g} / \mathrm{L}$ in more than $50 \%$ of treated water samples analyzed, followed by triazine herbicides (around 40\%) and benzimidazole fungicides (around 30\%).

Table 2 shows the detection frequency for the specific organic pollutants detected. It can be seen that most of the positive findings in raw leachate exceeded the $0.1 \mu \mathrm{g} / \mathrm{L}$ level. However, in treated water only ten contaminants surpassed this value in one or more occasions (six herbicides: terbumeton, terbutryn, terbuthylazine, terbacil, simazine and diuron; two fungicides: thiabendazole and imazalil; one insecticide: carbaryl; one PAH: naphthalene). Among them, the phenylurea herbicide diuron was present at concentrations higher than $0.1 \mu \mathrm{g} / \mathrm{L}$ in more than $50 \%$ of treated water samples analyzed (57\% of samples), due to its wide use in the Castellón province.

Summarizing data obtained in treated water, among 349 positive findings in the twoyears of monitoring, only 34 corresponded to concentrations higher than $0.1 \mu \mathrm{g} / \mathrm{L}$, although rarely exceeded $0.5 \mu \mathrm{g} / \mathrm{L}$. The only exceptions were carbaryl and diuron, with maximum concentrations of $1.5 \mu \mathrm{g} / \mathrm{L}$ (sample of January 2008) and $0.61 \mu \mathrm{g} / \mathrm{L}$ (sample of February 2008), respectively. In the case of 4-t-octylphenol, chlorphenvinphos, chlorpyrifos, diuron and simazine, priority substances in the Environmental Quality Standards (EQS) in the field of water [6], all of them were detected in some occasion in treated water but never exceeding the admissible maximum concentration referenced $(0.1,0.3,0.1,1.8$ and $4 \mu \mathrm{g} / \mathrm{L}$, respectively). 
As expected, the percentage of detections and concentration levels was notably higher in raw leachates in comparison to treated samples. Thus, among 477 positive findings in raw leachate, 373 exceeded $0.1 \mu \mathrm{g} / \mathrm{L}$. Several compounds were detected in all samples analyzed. Within the group of pesticides, the herbicides diuron, simazine, terbacil and terbutryn were detected in all the 20 water samples analyzed, reaching concentration levels as higher as $21 \mu \mathrm{g} / \mathrm{L}$ (terbacil, August 2008). Four insecticides (carbaryl, carbofuran, dimethoate and pirimicarb) were also found in all non-treated samples. The highest concentration level was reported for dimethoate in the sample of October 2008 $(82 \mu \mathrm{g} / \mathrm{L})$. In the case of fungicides, imazalil and triadimenol were detected in all samples as well, reaching maximum concentrations of $2.3 \mu \mathrm{g} / \mathrm{L}$ in both cases. Other compound, 4-t-octylphenol, used as precursor in the manufacture of non-ionic surfactants, was also found in all the samples analyzed, with a maximum concentration level of $5.6 \mu \mathrm{g} / \mathrm{L}$.

As illustrative examples, Figures 2 and 3 show UHPLC-MS/MS and GC-MS/MS chromatograms for treated and raw leachate water samples collected on March 2008. From all the results obtained, it seems that the treatment process applied (reverse osmosis) in the MSW treatment plant was rather efficient, as it notably reduced the concentration levels of organic contaminants found in raw leachate.

\section{Analysis of water samples by TOF}

As illustrated in the previous section, the combined use of GC-MS/MS and LC-MS/MS with triple quadrupole analyzers was a satisfactory approach for quantitative determination of around 100 selected contaminants in treated and raw leachate water samples. However, the list of target analytes was limited to a number of contaminants that, although relevant from environmental point of view, are not the only ones present in the samples. So, to have more realistic information about the pollution degree of 
these samples, the investigation of other non-selected contaminants would be necessary. TOF MS was chosen to this aim due to its great potential for wide-scope screening, as stated in the introduction section. Consequently, all water samples were also analyzed by GC-TOF MS and by LC-QTOF MS in order to investigate the presence of other contaminants not included in the list of target analytes. The sample treatment was the same as used for GC-MS/MS (GC-TOF MS analysis) and for UHPLC-MS/MS (UHPLC-QTOF MS analysis). The objective was to identify other pollutants present in the samples that could be added to the list of target analytes in future monitoring programs.

\section{Analysis by GC-TOF MS}

The use of GC-TOF MS allowed us to investigate other selected compounds thanks to the full spectrum acquisition at satisfactory sensitivity. In addition, the elucidation of several unknown compounds (non-target analytes) was tested. The methodological approach previously developed for screening and confirmation of organic micropollutants in water $[25,26]$ was applied in this project for searching target and non-target contaminants in wastewater samples.

The investigation of other selected compounds was carried out in a post-target way, as searching of the compound was performed after MS acquisition [23]. Up to 5 narrowwindow eXtracted Ion Chromatograms (nw-XIC), with a mass window of $0.02 \mathrm{Da}$, at selected $\mathrm{m} / \mathrm{z}$ ions were obtained for every compound. The application manager TargetLynx was employed to automatically process data and to confirm the identity of compounds detected in samples. Analyte confirmation was performed by comparing the experimental Q/q intensity ratios in samples with the theoretical ones, calculated from standards in solvent. The presence of at least two ions measured at their accurate mass and the compliance of their $\mathrm{Q} / \mathrm{q}$ ratio within specified tolerances [30] was required for a 
reliable confirmation. In the present work, a list of around 150 compounds (see Supplement Table 1), where many target analytes investigated by GC-MS/MS QqQ were also included, was investigated in treated and non-treated water samples. Calibration curves were included in every sequence of analysis; so, a semi-quantitative estimation of positive findings could be performed. Table 3 shows four pesticides that were detected in the samples analyzed. These compounds were not included in the target list of neither the GC-MS/MS nor LC-MS/MS method. Three of them were OP insecticides (diazinon, dichlorvos and fenthion) and were detected in several raw leachates, reaching concentration levels as high as $79 \mu \mathrm{g} / \mathrm{L}$ (fenthion, sample of October 2008). The fungicide diphenylamide was detected in only one raw sample (June 2007), although at high concentration $(152 \mu \mathrm{g} / \mathrm{L})$. In treated water, only diazinon was detected (6 out of 21 samples analyzed), always at concentrations higher than $0.1 \mu \mathrm{g} / \mathrm{L}$.

Investigation of non-target compounds in the samples was carried out by applying the ChromaLynx Application Manager. This software automatically detected peaks with a response over user-defined parameters, displayed their deconvoluted mass spectra to be searched in the library, and produced at hit list with positive matches (library match $>$ 700 was used as criterion). The formulas from the library hit were submitted to the elemental composition calculator and the five most intense ions were scored by exact mass measurement for the confirmation/rejection of finding [25]. Using this approach, several contaminants were discovered. These compounds were not included in the target list of QqQ-based methods nor the list of post-target GC-TOF MS. Table 3 shows the non-target compounds detected using this approach. Some of these compounds had been already detected by our group in environmental and biological samples using GCTOF MS [26, 31]. N-butyl benzenesulfonamide (N-BBSA) used in polyamide and copolyamide plastics and in the manufacturing of sulfonyl carbamate herbicides was the 
compound more frequently detected (100\% treated and $90 \%$ non-treated water). Diethyltoluamide, an insect repellent, was found in all raw water samples and in 8 treated water samples. Benzophenone, a UV filter used primarily as photoinitiator, fragrance enhancer, and also used in the manufacture of insecticides, agricultural chemicals and pharmaceuticals, was identified in around $50 \%$ of both treated and nontreated water. Other compounds frequently detected in non-treated waters were caffeine and the pharmaceuticals ibuprofen and benzenesulfonanilide.

As an illustrative example, Figure 4 shows a positive finding of ibuprofen in nontreated water using the GC-TOF MS non-target approach. Accurate mass confirmation automatically performed by the software for four representative ions led to the confirmation of the identity of ibuprofen with mass errors below $1 \mathrm{mDa}$ for three of them.

\section{Analysis by UHPLC-QTOF MS}

The analysis of samples by UHPLC-QTOF MS was carried out in a post-target way searching for around 500 compounds that were included in a home-made database. The list contained 377 pesticides and 40 transformation products (TP), as well as 47 antibiotics, 20 pharmaceuticals, and other emerging contaminants reported to have been detected in aquatic environment, such as cocaine or caffeine [27]. For investigation of these compounds, ChromaLynx XS software was used.

Briefly, this application manager automatically processes data, and obtains nw-XICs (mass window of $0.02 \mathrm{Da}$ ) at selected $\mathrm{m} / \mathrm{z}$ ions, usually those corresponding to protonated or deprotonated molecules, based on a selected list of accurate masses and retention times, if available. Besides, this software allows visualizing the complete spectrum of positive findings at accurate masses, which can be compared with a library, if available. This facilitates a rapid and simple review by cataloguing pollutants on 
colors, as a function of mass errors. In our case, a theoretical home-made library was built without the need of injecting reference standards. It showed the theoretical spectrum with information on molecular ion mass (typically $(\mathrm{M}+\mathrm{H})^{+}$in ESI positive) and the theoretical isotopic pattern.

Following this methodology, most of analytes detected by triple quadrupole were also confirmed by TOF MS. In addition, other contaminants not included in the target list of the QqQ methods were identified. Table 4 shows compounds not investigated by QqQ that were discovered in several samples analyzed. Antibiotics, such as erythromycin and clarythromycin, were detected by UHPLC-QTOF MS in around 5\% of treated water samples and around $50 \%$ of raw leachates. The analgesic paracetamol was found in more than $70 \%$ of samples analyzed. Atenolol, a beta-antagonist used primarily in cardiovascular diseases in the treatment of hypertension, was detected in $85 \%$ of samples. Metamizole, an anti-inflammatory drug commonly used as powerful analgesic and antipyretic, was found in $75 \%$ of raw samples and in $50 \%$ of treated water. Caffeine and the insecticide diazinon, which were already identified in some samples by using GC-TOF MS, were also found in around $40 \%$ of raw leachate and a few treated water samples. Paraxanthine, a caffeine metabolite, was detected in both raw and treated water (around 30\% samples). Cocaine was detected in only one sample out of the 20 raw leachates analyzed. However, benzoylecgonine, one of the main metabolites of cocaine, was detected in $95 \%$ of raw leachate and $60 \%$ of treated water samples. Finally, some pesticide TPs, concretely deethyl-terbumeton, 2-hydroxy-terbuthylazine and deethyl-2hydroxy-terbuthylazine, were also found in several samples.

As an example, Figure 5 shows a positive finding of diazinon in raw leachate using the UHPLC-QTOF MS post-target approach. The nw-XIC at $\mathrm{m} / z$ corresponding to the exact mass of diazinon $[\mathrm{M}+\mathrm{H}]^{+}$is shown together with its accurate mass spectrum and the 
theoretical one. Accurate mass confirmation automatically performed for the $[\mathrm{M}+\mathrm{H}]^{+}$ ion showed a mass error of $0.7 \mathrm{mDa}$.

In addition, the availability of a QTOF instrument made it feasible to perform MS/MS experiments to go further in the identification process of the compounds detected, thanks to the useful information given by product ion spectra at accurate mass. Fullacquisition accurate mass data were also processed in a non-target way [27], trying to elucidate "unknown" components detected in samples. The difference with respect to the GC-TOF MS approach was the use of only two ions (softer ionization in ESI in comparison to EI) and the use of the theoretical home-made library previously described, due to the non-availability of extensive and reproducible LC-MS commercial libraries. After processing MS data in the non-target approach, only five contaminants were discovered: paracetamol, cocaine, benzoilecgonine, caffeine and diazinon. All of them had been previously detected in the post-target screening, and corresponded to those analytes with sensitive response in TOF MS. The rest of compounds (see Table 4) could not be elucidated using this non-target approach due to either their low sensitivity and/or their low concentration level in the samples. It is important to remark that the LC-TOF MS screening of organic contaminants using a non-target approach may not be fully satisfactory at the moment, as the success of this approach gets notably worse at low analyte responses, being therefore less efficient than the post-target analysis. The non-availability of wide commercial reproducible libraries, as in GC with EI, is an important limitation at present. In fact, using non-target analysis only five compounds were elucidated, as stated above.

As an example of the non-target UHPLC-QTOF MS approach, Figure 6 shows a positive finding of paracetamol in non-treated leachate. Accurate mass confirmation 
automatically performed for two representative ions led to the confirmation of the identity of paracetamol in this sample with mass errors of 0 and $-0.7 \mathrm{mDa}$. 


\section{CONCLUSIONS}

Investigation of organic pollutants of wide polarity ranges in water requires the use of two complementary techniques: GC-MS, for the determination of non-polar/semi volatile analytes, and LC-MS, for more polar analytes. In this paper, an analytical strategy consisting on the combined use of GC-MS/MS and UHPLC-MS/MS, both with triple quadrupole analyzers, has been applied in order to investigate the presence of around 100 organic contaminants in treated and raw leachate samples from a Municipal Solid Waste treatment plant.

Pesticides have been the most commonly detected compounds in both type of samples, especially herbicides (phenylurea, triazine, uracil and carbamate), fungicides (benzimidazole, conazole and anilide) and insecticides (carbamate, organophosphorus and phenylthiadiazinone). Other contaminants widely detected were 4-t-octylphenol and several PAHs such as naphthalene, phenanthrene and pyrene.

As expected, the frequency of detections and pollutant concentrations in raw leachates was notably higher than in treated samples. Most of positive findings in non-treated samples were at concentrations above $0.1 \mu \mathrm{g} / \mathrm{L}$. However, in treated water very few compounds were detected at levels higher than $0.1 \mu \mathrm{g} / \mathrm{L}$, and rarely exceeded $0.5 \mu \mathrm{g} / \mathrm{L}$. From data obtained, it seems that the reverse osmosis treatment applied in the MSW treatment plant was rather efficient, as it notably reduced the concentration levels of organic contaminants found in raw leachates.

MS/MS techniques using triple quadrupole analyzer have shown a great potential in environmental analysis due to its high sensitivity and selectivity. However, tandem MS methods are developed on purpose for a limited list of target contaminants (around 100 organic contaminants in this work); so, other relevant pollutants that might be present in the samples would be ignored in these analyses. For this reason, all the samples were 
also analyzed by GC-TOF MS and UHPLC-QTOF MS in order to investigate the presence of many other contaminants, either in a post-target way (searching for selected pollutants after MS acquisition data) or in a non-target way (searching for unknowns without any previous selection nor information on the compounds to be investigated). This was feasible thanks to the full MS spectra acquisition by TOF analyzers, which offered the possibility of searching for a large number of contaminants with the help of the accurate mass information of the molecules and of the fragment ions. This has allowed discovering several compounds not included in the initial target list of organic contaminants. Other pesticides (diazinon, dichlorvos, diphenylamine and fenthion) and some TPs (deethyl-terbumeton, 2-hydroxy-terbuthylazine and deethyl-2-hydroxyterbuthylazine), pharmaceuticals (erythromycin, clarythromycin, atenolol, metamizole, benzenesulfonanilide, ibruprofen and paracetamol), drugs of abuse (cocaine and its metabolite benzoylecgonine), the UV filter benzophenone, N-BBSA, the insect repellent diethyltoluamide, or caffeine and its metabolite paraxanthine, are examples of compounds identified in additional analyses performed by TOF instruments. These discovered analytes could be included in the target quantitative methods applied in futures monitoring programs. This paper shows the potential of TOF MS for screening purposes, as this analyzer in combination with GC and LC is able to detect and identify a huge number of pollutants, making of it an excellent analytical tool for wide-scope screening in the environmental field.

\section{ACKNOWLEDGMENT}

The authors acknowledge the financial support from the Ministerio Español de Ciencia e Innovación (Project CTQ2009-12347), and also from Generalitat Valenciana as 
research group of excellence PROMETEO/2009/054. The authors are very grateful to the Serveis Centrals d'Instrumentació Científica (SCIC) of University Jaume I for the use of UHPLC-MS (TQD), GC-TOF MS (GCT) and UHPLC-QTOF MS (QTOF Premier). This work has been developed under financial support of RECIPLASA as a part of the project "Investigación de contaminantes orgánicos en las aguas de lixiviado de residuos urbanos de la planta de compostaje de Onda“. 


\section{REFERENCES}

[1] Pichon V (2000) J Chromatogr A 885:195-215

[2] Oman C (2001) Environ Sci Technol 35:232-239

[3] Schwarzbauer J, Heim S, Brinker S, Littke R (2002) Wat Res 36:2275-2287

[4] Council Directive 98/83/EC ( $3^{\text {rd }}$ November 1998) Off J Eur Commun L330

[5] Directive 2000/60/EC (23 ${ }^{\text {th }}$ October 2000) Off J Eur Commun L327

[6] Proposal of Directive COD/2006/0129 related to the Water policy: establishment of environmental quality standards EQS (amend. Directive 2000/60/EC) (17th July 2006) Brussels

[7] Díaz Cruz MS, Barceló D (2008) Chemosphere 72:333-342

[8] van Leeuwen SPJ, de Boer J (2008) J Chromatogr A 1186:161-182

[9] Giger W (2009) Anal Bioanal Chem 393:37-44

[10] Richardson SD (2009) Anal Chem 81:4645-4677

[11] Santos FJ, Galceran MT (2002) Trends Anal Chem 21:672-685

[12] Pitarch E, Medina C, Portolés T, López FJ, Hernández F (2007) Anal Chim Acta $583: 246-258$

[13] Pitarch E, Marín JM, López FJ, Hogendoorn E, Hernández F (2007) Intern J Environ Anal Chem 87:237-248

[14] Hernández F, Marín JM, Pozo OJ, Sancho JV, López FJ, Morell I (2008) Intern J Environ Anal Chem 88:409-424

[15] Kuster M, López de Alda M, Barceló D (2009) J Chromatogr A 1216:520-529

[16] Kasprzyk-Hordern B, Dinsdale RM, Guwy AJ (2008) Anal Bioanal Chem $391: 1293$ 
[17] Gracia-Lor E, Sancho JV, Hernández F, J Chromatogr A, (accepted, doi: 10.1016/j.chroma.2009.11.090)

[18] Batt AL, Kostich MS, Lazorchak JM (2008) Anal Chem 80:5021-5030

[19] Bijlsma L, Sancho JV, Pitarch E., Ibánez M, Hernández F (2009) J Chromatogr A 1216:3078-3089

[20] Wang J, Pang X, Ge F, Ma Z (2007) Toxicon 49:1120-1128

[21] Gervais G, Brosillon S, Laplanche A, Helen C (2008) J Chromatogr A 1202:163172

[22] Marín JM, Gracia-Lor E, Sancho JV, López FJ, Hernández F (2009) J Chrom A $1216: 1410-1420$

[23] Hernández F, Pozo OJ, Sancho JV, López FJ, Marín JM, Ibáñez M (2005) Trends Anal Chem 24:596-612

[24] Sancho JV, Pozo OJ, Ibáñez M, Hernández F (2006) Anal Bional Chem 386:987997

[25] Hernández F, Portolés E, Pitarch E, López FJ (2007) Anal Chem 79:9494-9504

[26] Portolés T, Pitarch E, López FJ, Sancho JV, Hernández F (2007) J Mass Spectrom 42:1175- 1185

[27] Ibáñez M, Sancho JV, McMillan D, Rao R, Hernández F (2008) Trends Anal Chem 27:481-489

[28] Grange AH, Genicola FA, Sovocool GW (2002) Rapid Commun Mass Spectrom $16: 2356-2369$

[29] Grange AH, Sovocool GW (2007) Environ Forensics 8:391-404 
[30] European Comission Decision 2002/657/EC (12 ${ }^{\text {th }}$ August 2002) Off J Eur Commun L221

[31] Hernández F, Portolés T, Pitarch E, López FJ (2009) J Mass Spectrom 44:1-11 


\section{FIGURE CAPTIONS}

Figure 1. Frequency of detection (\%) of different families of organic contaminants in treated and raw leachate samples collected from the MSW treatment plant between March 2007 and February 2009.

INS: insecticide, FG: fungicide, HB: herbicide, OC: organochlorine, ONP: octyl nonyl phenols, OP: organophosphorus, $\mathrm{PAH}$ : polycyclic aromatic hydrocarbons

Figure 2. UHPLC-MS/MS chromatograms for treated and raw leachate samples, both collected on $3^{\text {rd }}$ March 2008. Only the quantification transition (Q) is shown for every analyte (n.d., not detected).

Figure 3. GC-MS/MS chromatograms for treated and raw leachate samples, both collected on $3^{\text {rd }}$ March 2008. Only the quantification transition (Q) is shown for every analyte (n.d., not detected).

Figure 4. Identification of non-target ibruprofen by GC-TOF MS in a raw leachate sample collected on $28^{\text {th }}$ August 2008. (A) Extracted-ion chromatogram for four $m / z$ ions. (B) Commercial library mass spectrum of ibruprofen at nominal mass. (C) Deconvoluted accurate mass spectrum of ibuprofen in the sample (mass errors shown in $\mathrm{mDa}$ ).

Figure 5. Identification of diazinon by UHPLC-QTOF MS in a raw leachate sample collected on $31^{\text {th }}$ October 2008. (A) Extracted-ion chromatogram for $[\mathrm{M}+\mathrm{H}]^{+}$ ion, $m / z$ 305.1089. (B) Theoretical library mass spectrum of diazinon at nominal mass. (C) Accurate mass spectrum of diazinon in the sample.

Figure 6. Identification of non-target paracetamol by UHPLC-QTOF MS in a raw leachate sample collected on $10^{\text {th }}$ October 2008. (A) Extracted-ion chromatogram for two $\mathrm{m} / \mathrm{z}$ ions. (B) Theoretical library mass spectrum of 
paracetamol at nominal mass. (C) Deconvoluted accurate mass spectrum of paracetamol in the sample (mass errors shown in $\mathrm{mDa}$ ). 
SUPPLEMENT

Table 1. List of compounds investigated by GC-TOF MS in a post-target way

\begin{tabular}{|c|c|c|c|}
\hline 4-n-Nonylphenol & Cyfluthrin & Hexythiazox & PCB 180 \\
\hline 4-n-Octylphenol & Cyfluthrin_1 & Imazalil & PCB 189 \\
\hline 4-t-Octylphenol & Cyfluthrin_2 & Indeno( $(1,2,3$, cd $)$ pyrene & PCB 28 \\
\hline Acenaphthene & Cyfluthrin_3 & Iprodione & PCB 52 \\
\hline Acenaphthylene & Cyfluthrin_4 & Isodrin & PCB 77 \\
\hline Alachlor & Cypermethrin_1 & Isofenfos & PCB 81 \\
\hline Aldrin & Cypermethrin_2 & lambda-Cyhalothrin & Penconazole \\
\hline Anthracene & Cypermethrin_3 & Lindane & Pentachlorobenzene \\
\hline Atrazine & Cypermethrin_4 & Malathion & Permetrhin_1 \\
\hline Atrazine desethyl & Cyprodinil & Metalaxyl & Phenanthrene \\
\hline Atrazine desisopropyl & Deltamethrin & Metamidophos & Phosmet \\
\hline Azinphos methyl & Diazinon & Methacrifos & Pirimicarb \\
\hline BDE 100 & Dibenzo(a,h)anthracene & Methidathion & Pirimiphos ethyl \\
\hline BDE 138 & Dichlofluanide & Methiocarb & Pirimiphos methyl \\
\hline BDE 153 & Diclorvos & Methiocarb sulfone & Procymidone \\
\hline BDE 154 & Dieldrin & Metolachlor & Profenofos \\
\hline BDE 183 & Diflufenican & Metoxychlor & Propyzamide \\
\hline BDE 28 & Dimethoate & Mevinfos & Pyrazofos \\
\hline BDE 47 & Diphenylamine & Mirex & Pyrene \\
\hline BDE 66 & Endosulfan ether & Molinate & Quinalfos \\
\hline BDE 71 & Endosulfan sulfate & Naphthalene & Simazine \\
\hline BDE 85 & Ethion & Omethoate & tau-Fluvalinate_1 \\
\hline BDE 99 & Etrimfos & Oxadixyl & tau-Fluvalinate_2 \\
\hline Benzo(a)anthracene & Fenarimol & $p, p^{\prime}$-DDD & Tebuconazole \\
\hline Benzo(a)pyrene & Fenchlorfos & $p, p^{\prime}-\mathrm{DDE}$ & Tecnazen \\
\hline Benzo(b)fluoranthene & Fenitrothion & $p, p^{\prime}-\mathrm{DDT}$ & Terbacil \\
\hline Benzo(g,h,l)perylene & Fenoxycarb & Parathion ethyl & Terbumeton \\
\hline Benzo(k)fluoranthene & Fenthion & Parathion methyl & Terbumetona desethyl \\
\hline Bifentrin & Fenvalerate_1 & PCB 101 & Terbuthylazine \\
\hline Bupimirate & Fluoranthene & PCB 105 & Terbuthylazine desethyl \\
\hline Buprofezin & Fluorene & PCB 114 & Terbutryn \\
\hline Carbaryl_1 & Fonofos & PCB 118 & Tetradifon \\
\hline Carbaryl_2 & Forate & PCB 123 & Thiabendazole \\
\hline Chlorfenvinphos & Fosalone & PCB 126 & Trifluraline \\
\hline Chlorpropham & Fosfamidon & PCB 138 & $\alpha$-Endosulfan \\
\hline Chlorpyrifos & Heptachlor & PCB 153 & $\beta$-Endosulfan \\
\hline Chlozolinate & Heptachlor epoxide A & PCB 156 & \\
\hline Chlropyriphos methyl & Heptachlor epoxide B & PCB 157 & \\
\hline Chrysene & Heptenofos & PCB 167 & \\
\hline Coumafos & Hexachlorobenzene & PCB 169 & \\
\hline
\end{tabular}


Table 1. List of target compounds included in the analyses (method 1: GC-MS/MS; method 2: UHPLC-MS/MS)

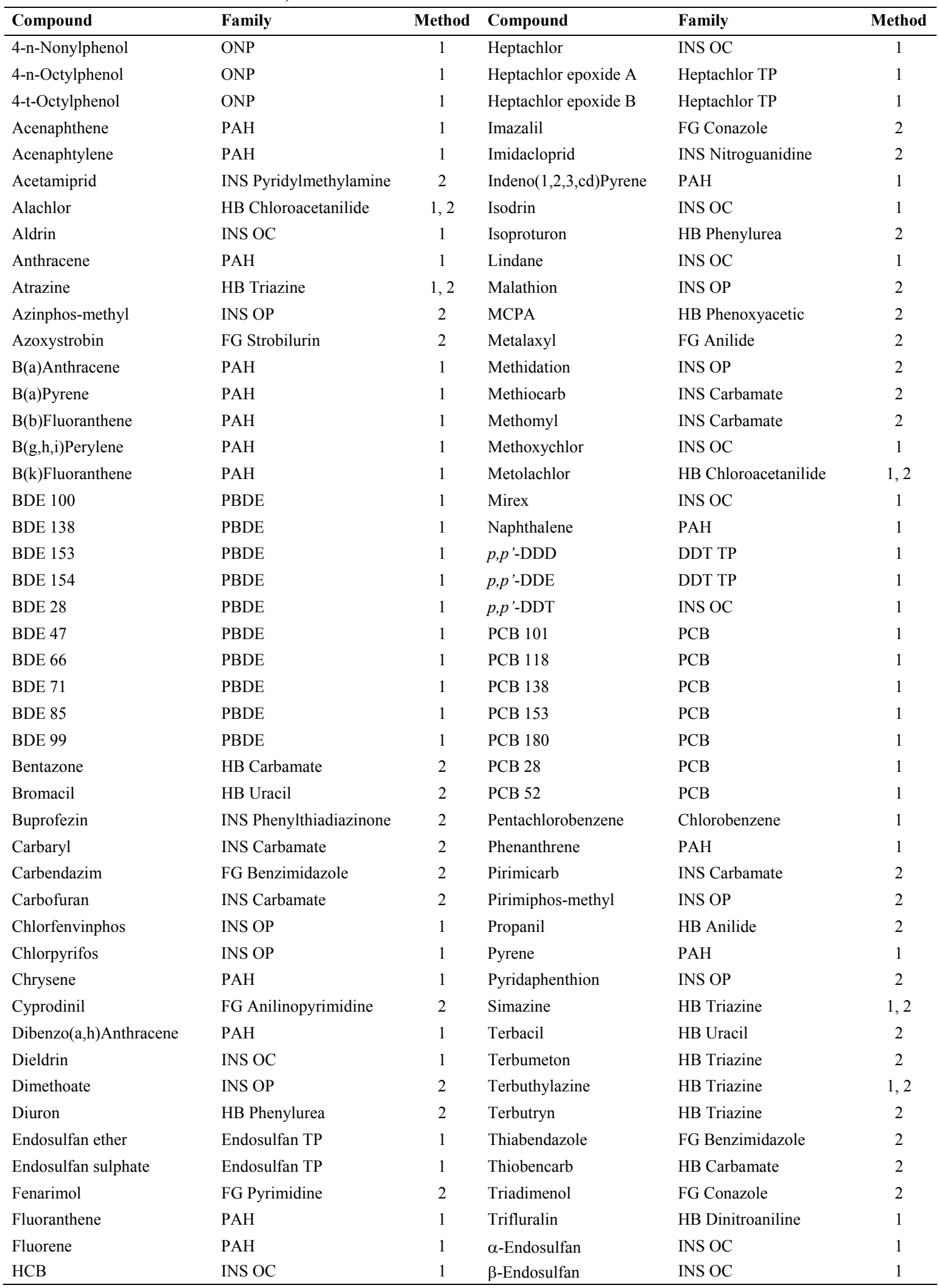

FG: fungicide; HB: herbicide; INS: insecticide; OC: organochlorine; ONP: octyl nonyl phenols; OP: organophosphorus; PAH: polycyclic aromatic hydrocarbons; PBDE: polybrominated diphenyl ether; TP: transformation product 
Table 2. Results obtained from UHPLC-MS/MS and GC-MS/MS target analysis of water samples from the MSW treatment plant between March 2007-February 2009 (total number of samples: 21 treated and 20 non-treated).

\begin{tabular}{|c|c|c|c|c|c|c|}
\hline \multirow[b]{2}{*}{ Compound } & \multicolumn{2}{|c|}{ \% positive samples } & \multicolumn{2}{|c|}{$\begin{array}{l}\text { \% samples } \\
>0.1 \mu \mathrm{g} / \mathrm{L}\end{array}$} & \multicolumn{2}{|c|}{$\begin{array}{c}\text { Maximum level } \\
(\mu \mathrm{g} / \mathrm{L})\end{array}$} \\
\hline & $\begin{array}{c}\text { Non- } \\
\text { treated }\end{array}$ & Treated & $\begin{array}{c}\text { Non- } \\
\text { treated }\end{array}$ & Treated & $\begin{array}{c}\text { Non- } \\
\text { treated }\end{array}$ & Treated \\
\hline Acetamiprid & 0 & 9.5 & 0 & 0 & nd & $<0.025$ \\
\hline Atrazine & 5 & 5 & 0 & 0 & $<0.025$ & $<0.025$ \\
\hline Azinphos-methyl & 15 & 0 & 10 & 0 & 4.3 & nd \\
\hline Azoxystrobin & 30 & 29 & 30 & 0 & 0.41 & $<0.025$ \\
\hline B(a)Pyrene & 0 & 5 & 0 & 0 & nd & $<0.025$ \\
\hline Bromacil & 75 & 43 & 50 & 0 & 14 & 0.03 \\
\hline Buprofezin & 65 & 57 & 35 & 0 & 1.0 & $<0.025$ \\
\hline Carbaryl & 100 & 48 & 90 & 14 & 40 & 1.5 \\
\hline Carbendazim & 95 & 81 & 75 & 0 & 41 & 0.08 \\
\hline Carbofuran & 100 & 71 & 95 & 0 & 43 & 0.10 \\
\hline Chlorfenvinphos & 75 & 57 & 75 & 0 & 3.6 & 0.082 \\
\hline Chlorpyrifos & 55 & 38 & 50 & 0 & 7.5 & $<0.025$ \\
\hline Dieldrin & 5 & 0 & 5 & 0 & 1.3 & nd \\
\hline Dimethoate & 100 & 48 & 85 & 0 & 82 & 0.10 \\
\hline Diuron & 100 & 95 & 100 & 57 & 19 & 0.61 \\
\hline Fluorene & 5 & 0 & 0 & 0 & $<0.025$ & nd \\
\hline Imazalil & 100 & 48 & 65 & 5 & 2.3 & 0.31 \\
\hline Imidacloprid & 5 & 5 & 0 & 0 & $<0.025$ & $<0.025$ \\
\hline Isoproturon & 5 & 5 & 0 & 0 & $<0.025$ & $<0.025$ \\
\hline Lindane & 5 & 0 & 0 & 0 & $<0.025$ & nd \\
\hline Malathion & 75 & 24 & 70 & 0 & 64 & 0.04 \\
\hline MCPA & 55 & 29 & 50 & 0 & 10 & 0.03 \\
\hline Metalaxyl & 95 & 62 & 40 & 0 & 4.4 & $<0.025$ \\
\hline Methidation & 40 & 5 & 15 & 0 & 13 & $<0.025$ \\
\hline Methiocarb & 55 & 9.5 & 30 & 0 & 1.6 & 0.030 \\
\hline Naphthalene & 55 & 48 & 55 & 14 & 15 & 0.31 \\
\hline 4-t-Octylphenol & 100 & 86 & 85 & 0 & 5.6 & 0.044 \\
\hline Phenanthrene & 85 & 57 & 60 & 0 & 1.3 & $<0.025$ \\
\hline Pirimicarb & 100 & 71 & 50 & 0 & 13 & $<0.025$ \\
\hline Pirimiphos-methyl & 15 & 0 & 5 & 0 & 0.13 & nd \\
\hline Pyrene & 60 & 43 & 50 & 0 & 0.42 & $<0.025$ \\
\hline Simazine & 100 & 81 & 65 & 9.5 & 17 & 0.23 \\
\hline Terbacil & 100 & 81 & 100 & 5 & 21 & 0.14 \\
\hline Terbumeton & 85 & 67 & 75 & 5 & 29 & 0.16 \\
\hline Terbuthylazine & 95 & 81 & 95 & 14 & 40 & 0.48 \\
\hline Terbutryn & 100 & 71 & 95 & 9.5 & 14 & 0.20 \\
\hline Thiabendazole & 95 & 90 & 85 & 29 & 14 & 0.37 \\
\hline Thiobencarb & 35 & 43 & 15 & 0 & 1.4 & $<0.025$ \\
\hline Triadimenol & 100 & 71 & 60 & 0 & 2.3 & 0.06 \\
\hline
\end{tabular}

nd: not detected 
Table 3. Results obtained from GC-TOF MS analysis of water samples from the MSW treatment plant between March 2007 - February 2009 (total number of samples: 21 treated and 20 non-treated).

\begin{tabular}{|c|c|c|}
\hline \multirow[b]{2}{*}{ Compound } & \multicolumn{2}{|c|}{$\begin{array}{l}\text { \% positive } \\
\text { samples }\end{array}$} \\
\hline & Treated & $\begin{array}{c}\text { Non- } \\
\text { treated }\end{array}$ \\
\hline \multicolumn{3}{|l|}{ Post-Target approach } \\
\hline Diazinon & 28 & 55 \\
\hline Dichlorvos & 0 & 5 \\
\hline Diphenylamine & 0 & 5 \\
\hline Fenthion & 0 & 5 \\
\hline \multicolumn{3}{|l|}{ Non-target approach } \\
\hline Benzenesulfonanilide & 5 & 70 \\
\hline Benzoguanamine & 0 & 5 \\
\hline Benzophenone & 38 & 55 \\
\hline BHT & 10 & 5 \\
\hline BHT-CHO & 5 & 10 \\
\hline n-Butylbenzenesulfonamide & 100 & 90 \\
\hline Caffeine & 5 & 35 \\
\hline Cotinine & 5 & 0 \\
\hline 3,4-Dichloroaniline & 5 & 10 \\
\hline Diethyltoluamide & 38 & 100 \\
\hline 8-Hydroxyquinoline & 5 & 0 \\
\hline Ibuprofen & 10 & 30 \\
\hline Ibuprofen, trimethylsilylesther & 5 & 0 \\
\hline Methylparaben & 5 & 20 \\
\hline Nicotine & 0 & 5 \\
\hline Triacetin & 0 & 5 \\
\hline 3,4,5-Trichlorobenzenamine & 0 & 5 \\
\hline
\end{tabular}

nd: not detected 
Table 4. Results obtained from UHPLC-QTOF MS analysis of water samples from MSW treatment plant between March 2007-February 2009 (total number of samples: 21 treated and 20 non-treated).

\begin{tabular}{|c|c|c|}
\hline \multirow{2}{*}{ Compound } & \multicolumn{2}{|c|}{ \% positive samples } \\
\hline & Treated & Non-treated \\
\hline \multicolumn{3}{|l|}{ Post-target approach } \\
\hline Atenolol & 85 & 85 \\
\hline Benzoylecgonine* & 60 & 95 \\
\hline Caffeine* & 40 & 43 \\
\hline Clarythromycin & 5 & 45 \\
\hline Cocaine* & 0 & 5 \\
\hline Diazinon* & 5 & 42 \\
\hline Erythromycin & 5 & 65 \\
\hline Metamizole* & 50 & 75 \\
\hline Paracetamol & 70 & 84 \\
\hline Paraxanthine & 25 & 35 \\
\hline deethyl-Terbumeton & 10 & 15 \\
\hline deethyl-2-hydroxy-Terbuthylazine & 35 & 55 \\
\hline 2-hydroxy-Terbuthylazine & 50 & 70 \\
\hline
\end{tabular}


INS OC

INS Nitroguanidine $\square$

INS Pyridylmethylamine

\section{Treated leachate}

HB Phenoxyacetic

FG Strobilurin

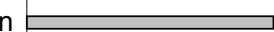

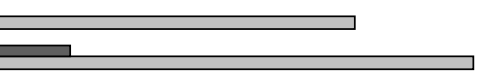

INS Phenylthiadiazinone $\square$

FG Anilide

INS OP

FG Conazole

INS Carbamate

HB Uracil

HB Triazine

ONP

FG Benzimidazole

HB phenylurea
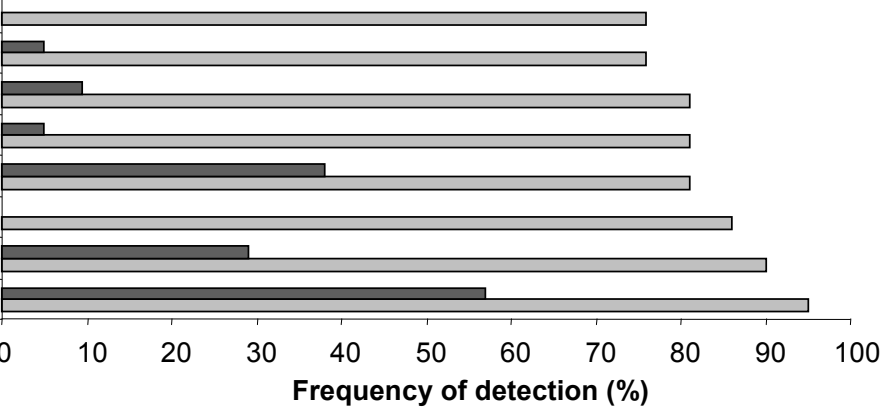

$\%$ positive samples

$\%$ positive samples $>0.1 \mu \mathrm{g} / \mathrm{L}$

INS Pyridylmethylamine

INS Nitroguanidine $\square$

INS OC

Raw leachate

FG Strobilurin

HB Carbamate

HB Phenoxyacetic

INS Phenylthiadiazinone

$\mathrm{PAH}$

FG Anilide

ONP

NS OP

INS Carbamate

HB Uracil

HB Triazine

HB Phenylurea

FG Conazole

FG Benzimidazole
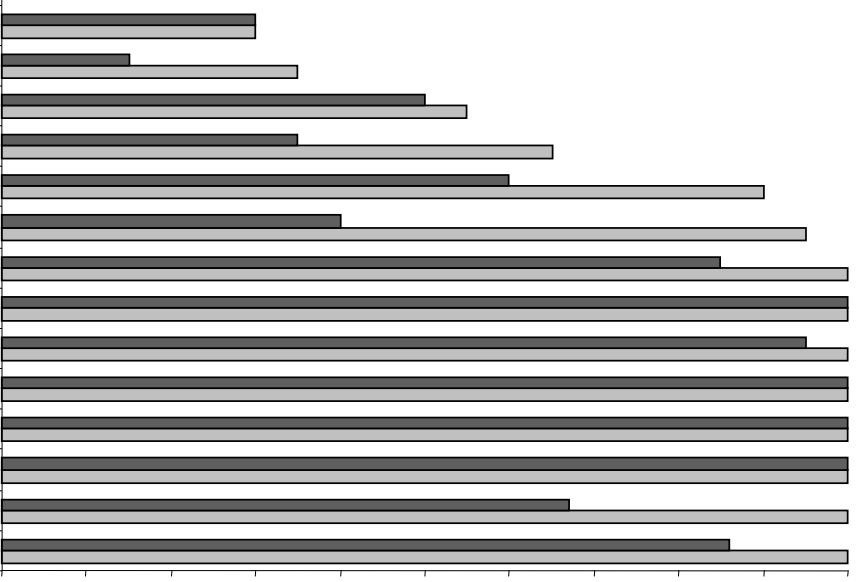

$\begin{array}{lllllllllll}0 & 10 & 20 & 30 & 40 & 50 & 60 & 70 & 80 & 90 & 100\end{array}$

Frequency of detection (\%)

Figure 1 

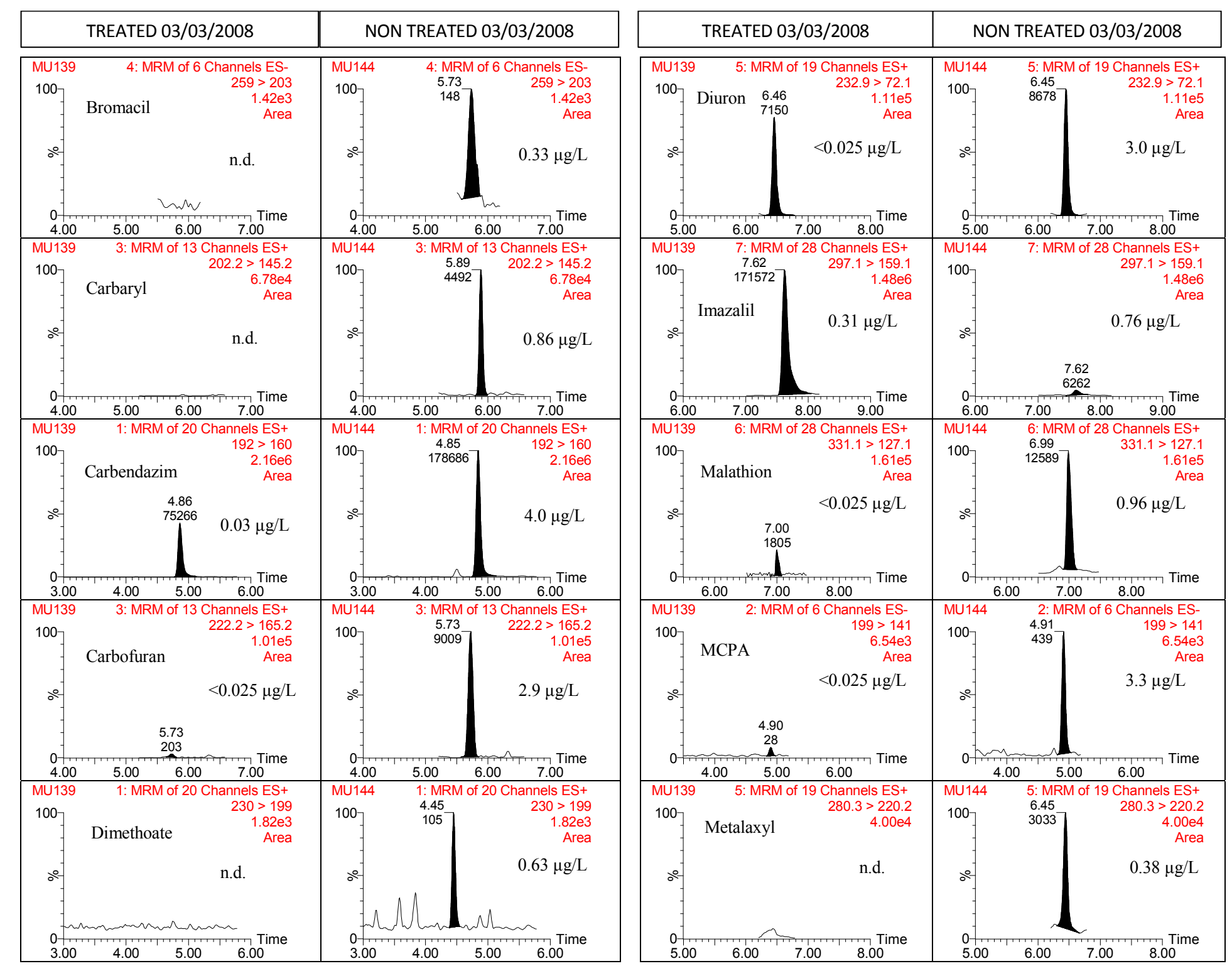

Figure 2 


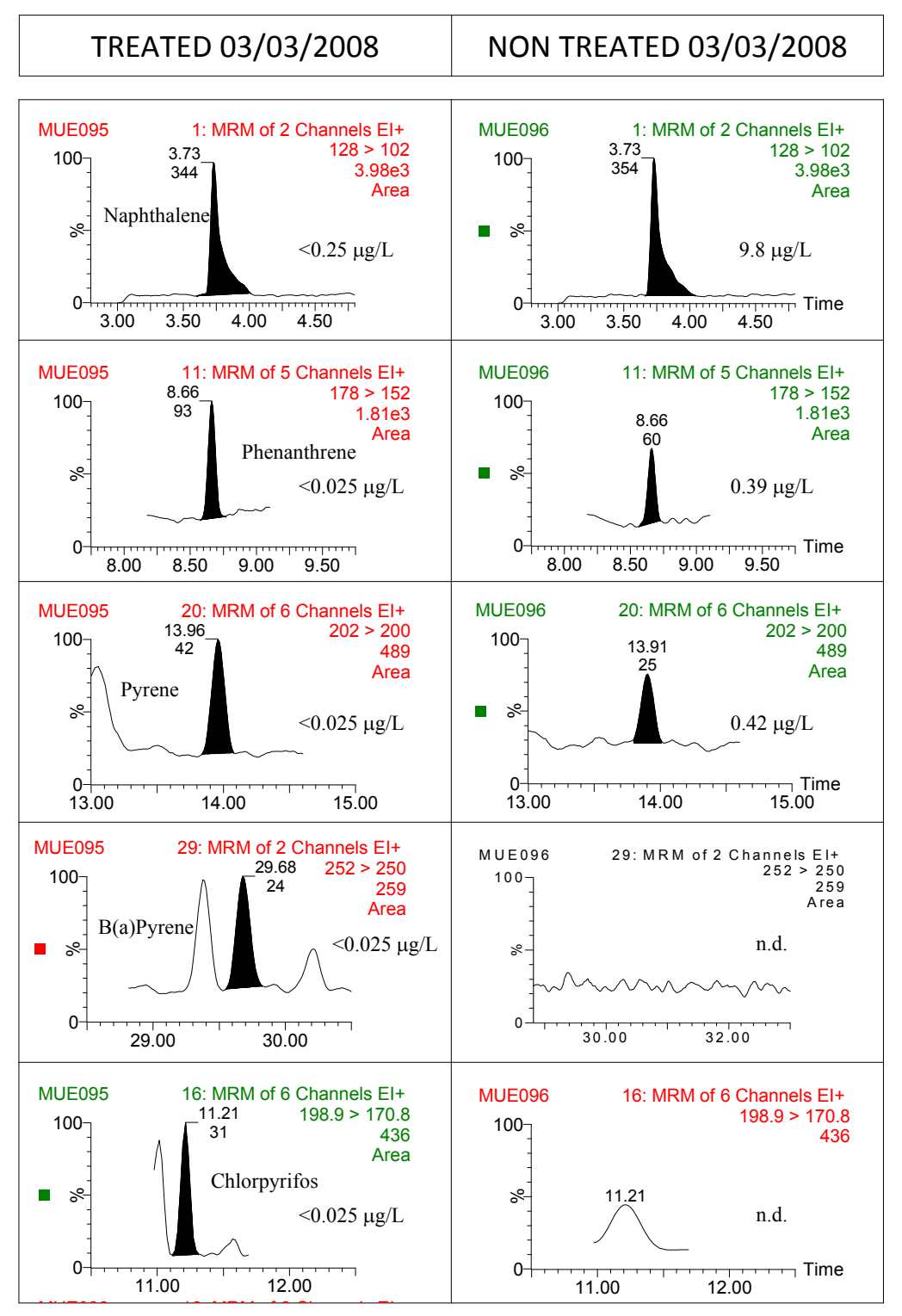

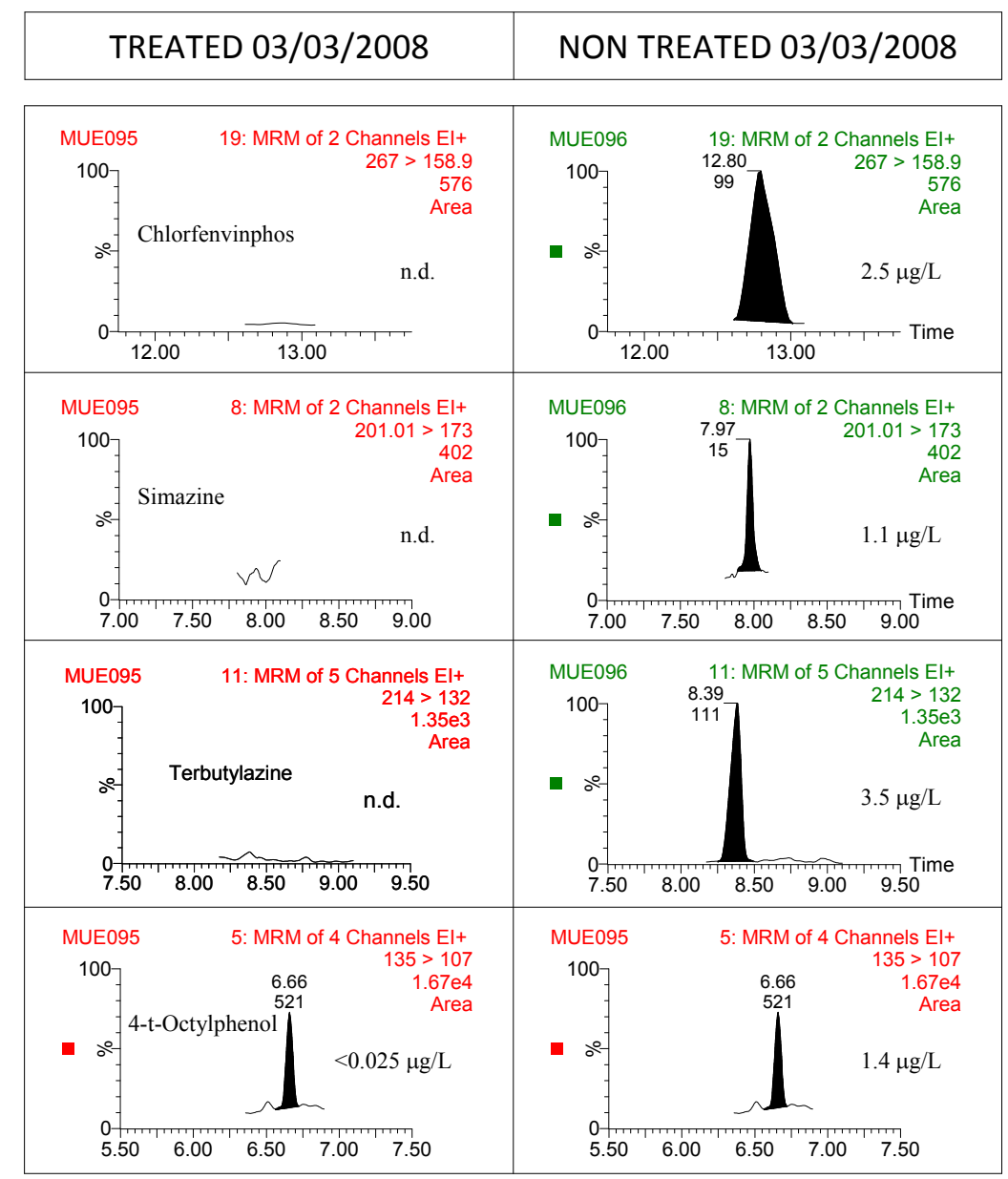

Figure 3 



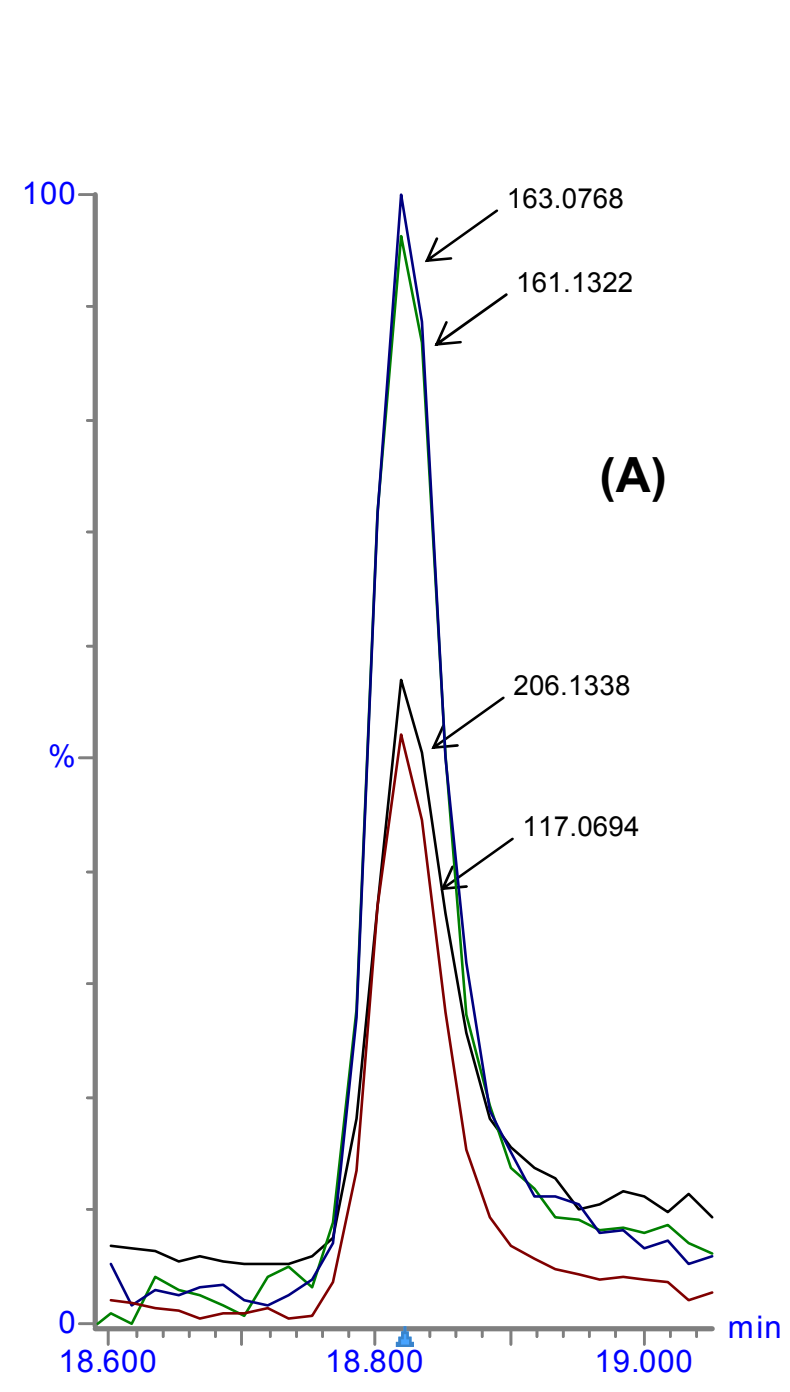

Library: Ibuprofen
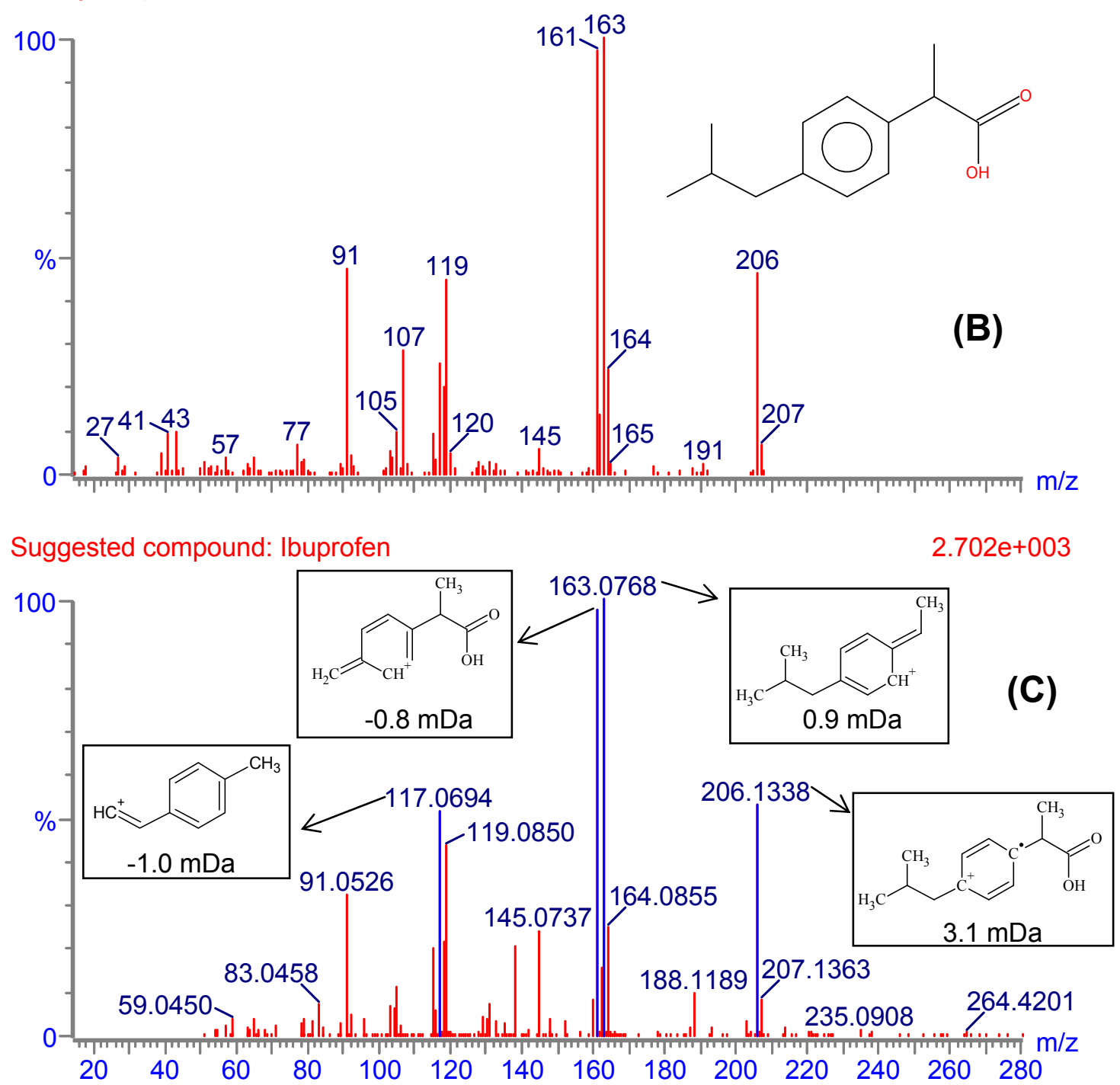

Figure 4 


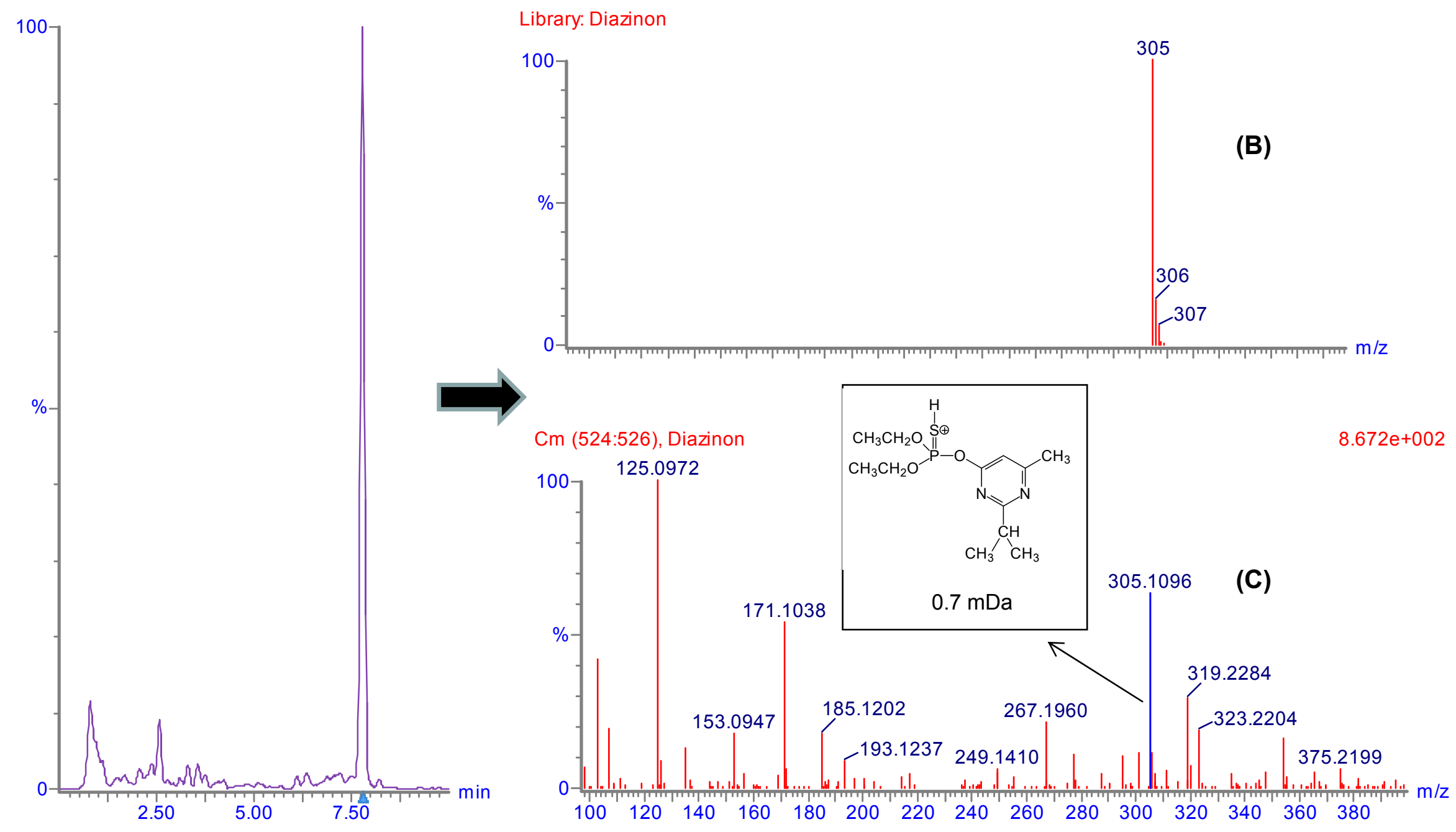

(A)

Figure 5 

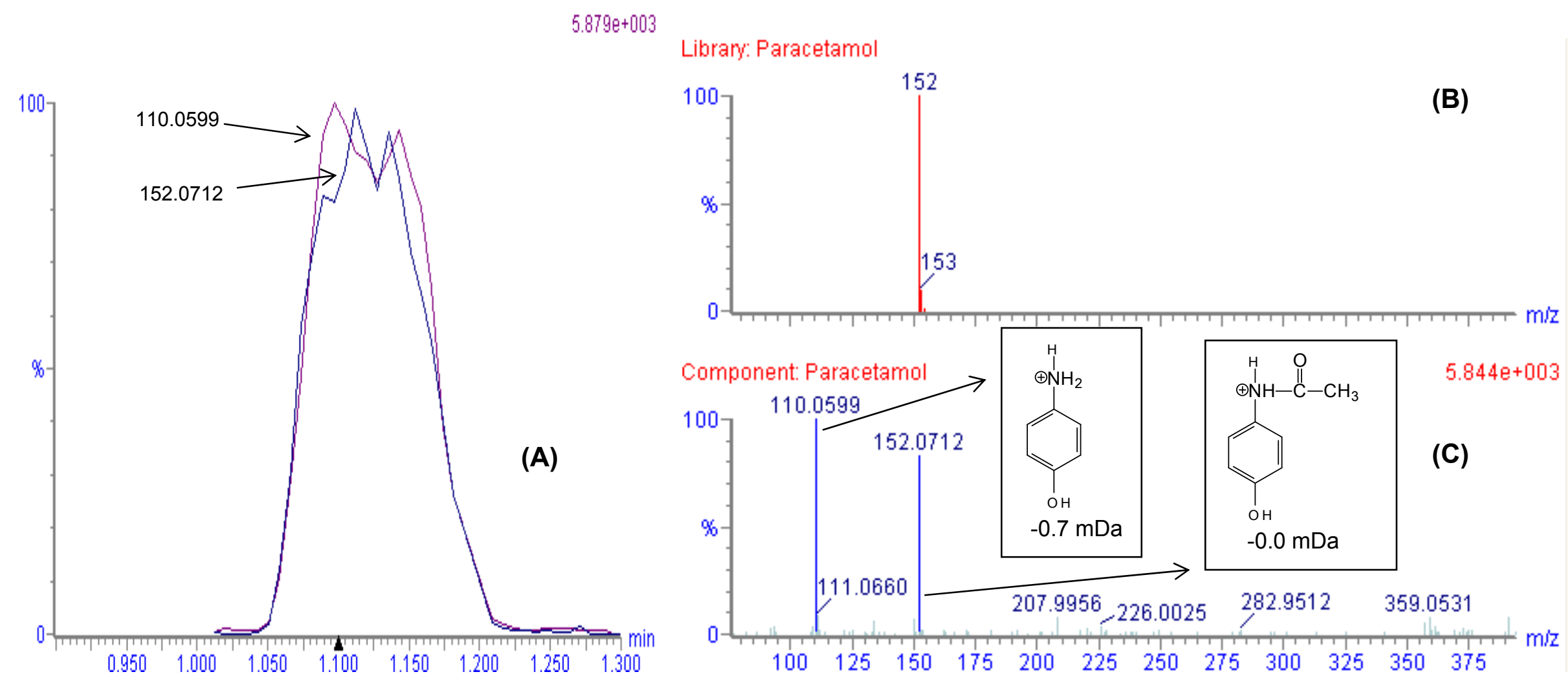

Figure 6 